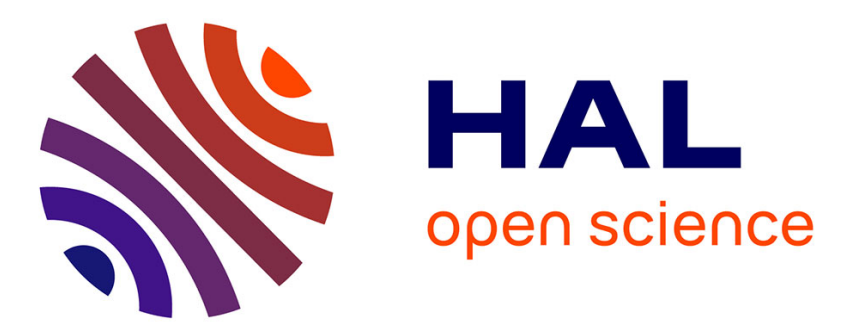

\title{
In-situ X-Rays Diffraction and Multiscale Modeling of Shape Memory Alloys
}

Mame Daro Fall, Olivier Hubert, Karine Lavernhe Taillard, Anne Maynadier

\section{To cite this version:}

Mame Daro Fall, Olivier Hubert, Karine Lavernhe Taillard, Anne Maynadier. In-situ X-Rays Diffraction and Multiscale Modeling of Shape Memory Alloys. SEM 2014, 2014, Greenville, United States. 8 p. hal-01021810

\author{
HAL Id: hal-01021810 \\ https://hal.science/hal-01021810
}

Submitted on 9 Jul 2014

HAL is a multi-disciplinary open access archive for the deposit and dissemination of scientific research documents, whether they are published or not. The documents may come from teaching and research institutions in France or abroad, or from public or private research centers.
L'archive ouverte pluridisciplinaire HAL, est destinée au dépôt et à la diffusion de documents scientifiques de niveau recherche, publiés ou non, émanant des établissements d'enseignement et de recherche français ou étrangers, des laboratoires publics ou privés. 


\title{
In-situ X-Rays Diffraction and Multiscale Modeling of Shape Memory Alloys
}

\author{
M.D. Fall ${ }^{1, *}$, O. Hubert ${ }^{1}$, K. Lavernhe-Taillard ${ }^{1}$, and A. Maynadier ${ }^{2}$ \\ ${ }^{1}$ LMT Cachan (ENS Cachan/CNRS UMR 8535/PRES UniverSud Paris) \\ 61 Avenue du Président Wilson, F-94235 Cachan Cedex, France \\ ${ }^{2}$ LaMCoS (INSA Lyon / UMR 5229) \\ 18-20, rue des Sciences, F-6962 Villeurbanne, cedex, France \\ *Corresponding author : fall@lmt.ens-cachan.fr
}

\begin{abstract}
Increasing use of Shape Memory Alloys (SMA) for complex applications requires a robust modeling of phenomena governing their behavior. The development of micro-macro multiaxial model is relevant. Such approach relies the definition of transition scale rules, depending on the microstructure, and a description of the behavior of constituents. On the other hand, it requires experiments for identification of parameters such as enthalpies or kinetic constants and validation of the model. In this paper, in situ X-Ray Diffraction (XRD) measurements are performed during tensile tests and heating-cooling cycles. XRD permits monitoring of the average volume fraction of phases in presence. Results will be used for the validation of a multiscale and multiphased model.
\end{abstract}

KEY WORDS: shape memory alloys (SMA), phase transformation, pseudoelasticity, X Ray diffraction (XRD).

\section{INTRODUCTION}

Shape Memory Alloys (SMA) are widely used in many industrial fields such as aerospace, automotive, biomedical, and even the clothing industry. Their interest lies in their ability to recover their original shape (as suggest their name!) by simply heating them. Indeed, they combine two interesting properties: the so-called shape memory effect and a pseudo elastic behavior (shape recovery after large deformation above 8\%). Such interesting properties are to be associated to the occurrence of a solid-solid phase transformation involving a high temperature stable phase called austenite (A) and a lower symmetry low temperature stable phase called martensite $(\mathrm{M})$ exhibiting many variants. Indeed SMA behavior exhibits a high thermomechanical coupling since phase transition can be driven thermally and /or mechanically. Democratization of the use of such materials requires nevertheless the overcome of some major difficulties regarding their behavior and so their modeling. One first difficulty is that the phase transformation is associated with thermal phenomena: heat loss for A to $\mathrm{M}$ transformation and heat absorption for the inverse transition. These thermal phenomena are at the origin of strain localizations during a strengthening. Phenomena like martensite reorientation by variant selection under complex multiaxial mechanical loadings is another major difficulty. A final difficulty is the appearance of some intermediate $\mathrm{R}$ (rhombohedral)phase depending on the temperature-stress path. A multiaxial multiscale modelling for SMA thermomechanical behaviour has been developed at LMT-Cachan [1]. This model allows to reproduce appearance/disappearance/re-orientation of A, RPhase or $\mathrm{M}$ variants at the microscale depending on their free energy associated to various loading conditions. Localization and homogenization rules are used for scale transitions. Among other results, this model permits an estimation of phase fractions and orientation so that in situ X-Ray Diffraction (XRD) may represent an interesting tool in order to validate the modeling. This paper is focused on the presentation of the experimental set-up that allowed us to get the measurements of phase volume fractions' evolution under simple loadings i.e. cooling and heating at zero stress and tensile tests at room temperature, by X Ray measurements. Diffractograms reported in the text have been obtained with a texturized nickeltitanium SMA exhibiting both martensitic and intermediate R-phase transformation. They consist in intensities as function of Bragg angular positions. Powder diffraction databases are almost used for identification of diffracting planes and associated phases. Quantitative analysis (estimation of volume fraction ratio) consists in measuring integrated intensities (or heights) 
and comparing the intensities ratio taking account of the crystallographic texture of the material [2].

\section{MOTIVATION}

Increasing use of Shape Memory Alloys (SMA) for complex applications requires a robust modeling of phenomena governing their behavior. The development of micro-macro multiaxial model is relevant. Such approach relies the definition of transition scale rules, depending on the microstructure, and an appropriate description of the behavior of constituents. A multiscale model has been proposed at LMT Cachan [1]. This model is able to predict the phase constituents and orientation at a given multiaxial stress level and temperature. It has been developed in a pseudo reversible framework. Indeed the model is based on the comparison of the free energies of each variant and calculation of associated volume fractions thanks to a probabilistic approach at the single crystal scale. Averaging operations allow calculating the macroscopic quantities at the polycrystalline scale. Obviously some experiments are required for identification of parameters and/or validation of the model. This second point is addressed in the paper. In situ X-Ray Diffraction (XRD) measurements are performed during tensile tests and heating-cooling cycles. XRD permits monitoring of the average volume fraction of phases in presence [3] [4]. Its operation requires the coupling of three different models: the multiscale modeling, diffraction pattern and geometric diffraction apparatus modeling on the other hand. Comparisons between experimental and modeled diffratograms lead to conclude about the model quality.

\section{MATERIAL AND EXPERIMENTAL SET UP}

$\mathrm{Ni}_{49.95 \mathrm{at} \%} \%$ Ti sample

The specimen consists in a thin plate of polycrystalline nickel-titanium (Ni-49.95at\% $\mathrm{Ti}$ ) SMA. Samples have a rectangular section of $20 \times 2 \mathrm{~mm}^{2}$. The forming process consists in a cold-rolling followed by a heat treatment of 2 minutes at $4800^{\circ} \mathrm{C}$ in salt bath. For Nickel-titanium SMA, the phase transformation consists usually in the appearance of a low temperature monoclinic martensite phase inside a high temperature mother body-cubic-centered austenite phase. Depending on exact composition and manufacture process, martensitic transition is sometimes preceded by the appearance of an intermediate phase called R-phase which unit cell is rhombohedral [5]. A Differential Scanning Calorimetry (DSC) measurement has first been performed to get the main characteristics of our sample. Results reported in Figure 1 show that the sample undergoes a double phase transition. Two successive thermal peaks occur during cooling associated to austenite to R-phase for the high temperature peak, and R-phase to martensite for the low temperature peak. DSC measurements also give an estimation of the

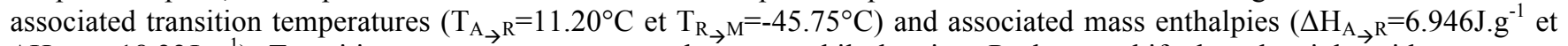
$\left.\Delta \mathrm{H}_{\mathrm{R}_{\rightarrow} \mathrm{M}}=18.22 \mathrm{~J}_{\mathrm{g}} \mathrm{g}^{-1}\right)$. Transition temperatures are not the same while heating. Peaks are shifted to the right with respect to cooling. This leads to the unique peak observed in the figure corresponding to a martensite-austenite transition $\left(\mathrm{T}_{\mathrm{M}_{\rightarrow} \mathrm{A}}=16.86^{\circ} \mathrm{C}\right.$ et $\left.\Delta \mathrm{H}_{\mathrm{M}_{\rightarrow} \mathrm{A}}=24.13 \mathrm{J.g}^{-1}\right)$. This heat absorption may involve a transient R-phase transformation.

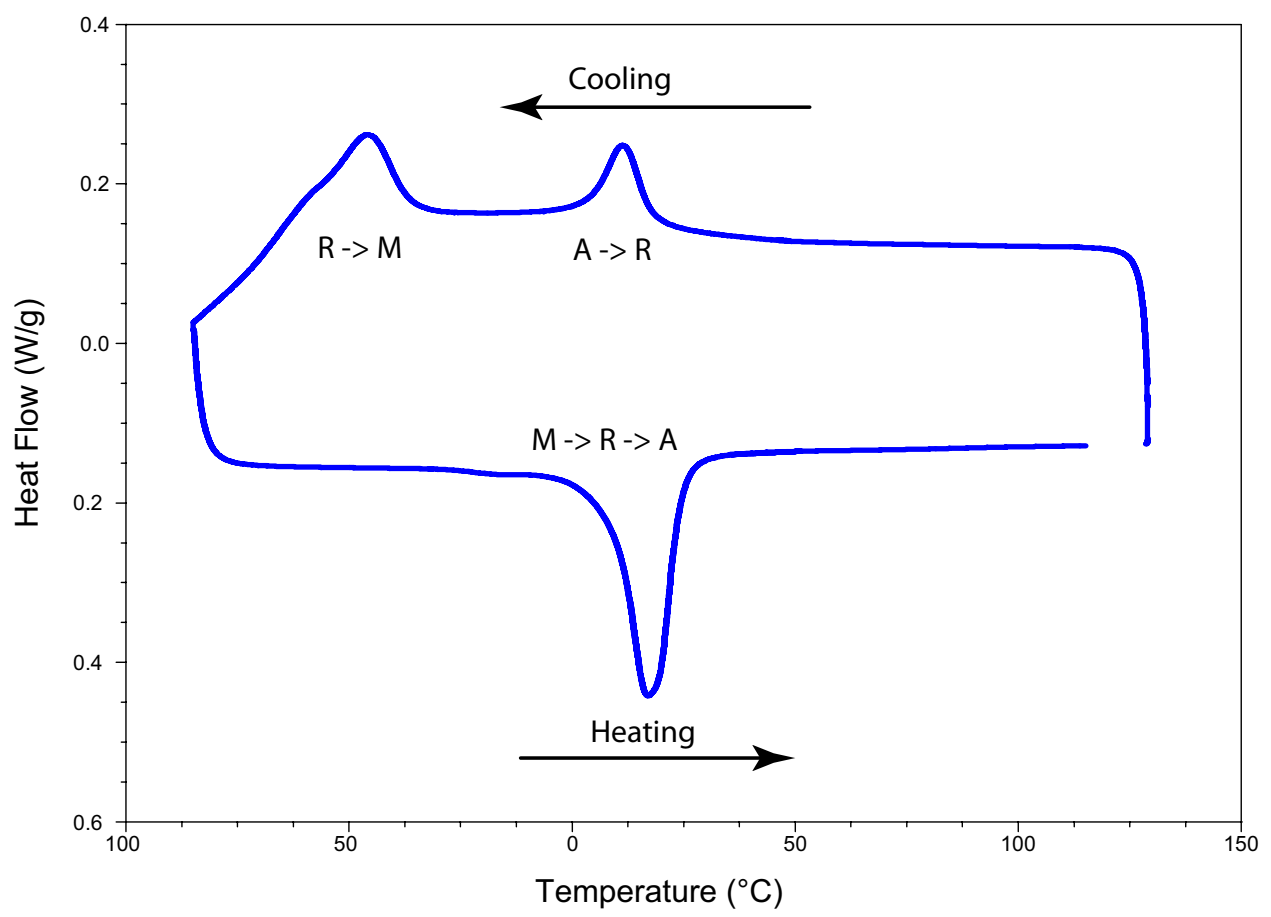

Figure 1 - DSC analysis of $\mathrm{Ni}_{-49.95 a t \%}$ Ti sample (courtesy of V.Delobelle - SIMAP-GPM2) 
Tests and Experimental Devices

We use an in situ $\mathrm{X}$ ray diffractometer (Figures 2 and 3). It consists on a goniometer for positioning the incident beam and $\mathrm{X}$ ray tube. Source chosen for diffraction is Cobalt $(\mathrm{K} \alpha$ ray $-0.1789 \mathrm{~nm})$. Diffracted rays are measured thanks to a curved detector (INEL CPS 180) covering a large range of angular detection $\left(2 \theta\right.$ range $\left.=120^{\circ}\right)$. A $1 \mathrm{~mm}$ diameter beam with fixed $50^{\circ}$ incident angle is used. For an improved ratio between main peaks and background, acquisitions duration is fixed to $10 \mathrm{~min}$ under $20 \mathrm{~mA}$ current and $30 \mathrm{kV}$ acceleration voltage. Sample's upper surface underwent an electrochemical polishing to improve the $\mathrm{X}$ ray diffraction quality. The first test performed is a cooling/heating cycle. Temperature is controlled using a Peltier effect apparatus made of a heating or cooling plate and a thermocouple for feedback control (Figure 2). The plate can heat up to $50^{\circ} \mathrm{C}$ but can't reach low temperature needed for full martensitic transition. A liquid nitrogen flow is added to reach the martensitic transition temperature. This flow avoids the appearance of ice crystals. The second experience is a uniaxial tensile test at room temperature. Sample gauge length is $80 \mathrm{~mm}$. Measurements were done on a hydraulic device available at LMT-Cachan (ASTREE) allowing us to keep fixed the central point of sample (figure 3). We use two coaxial horizontal hydraulic actuators for the uniaxial loading. Loading force and global displacement are measured. Loading is displacement controlled, with rate set to $0.01 \mathrm{~mm} / \mathrm{s}$. The test is performed at room temperature $\left(26^{\circ} \mathrm{C}\right)$, the material being consequently initially in the austenitic state.

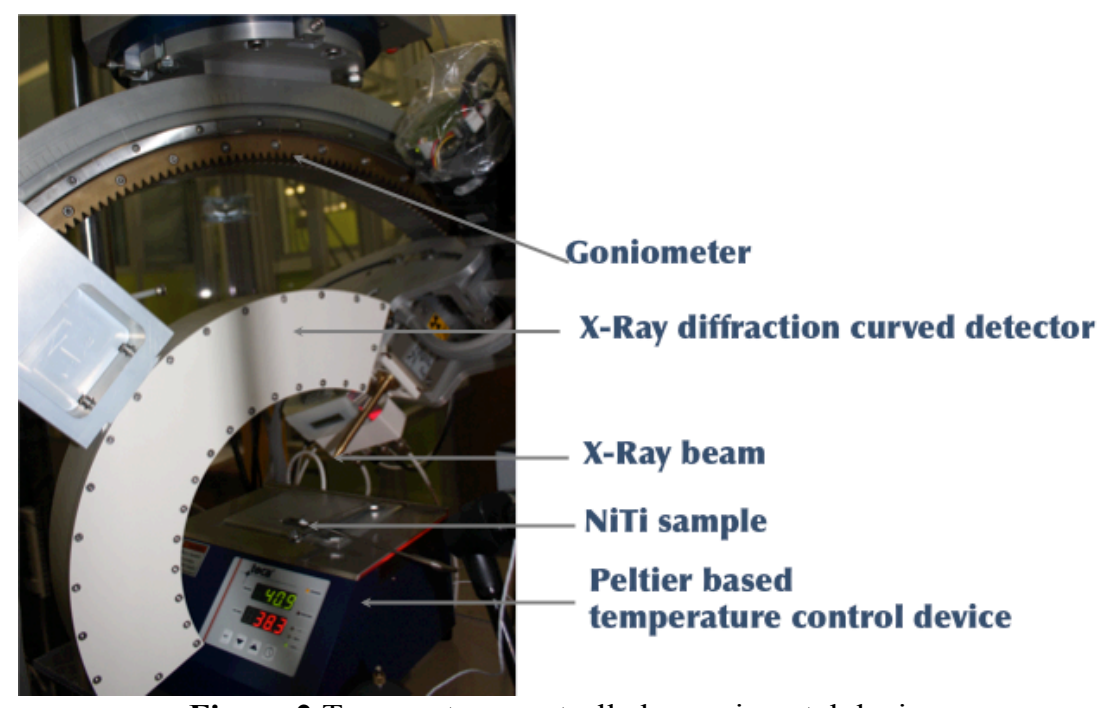

Figure 2 Temperature controlled experimental device

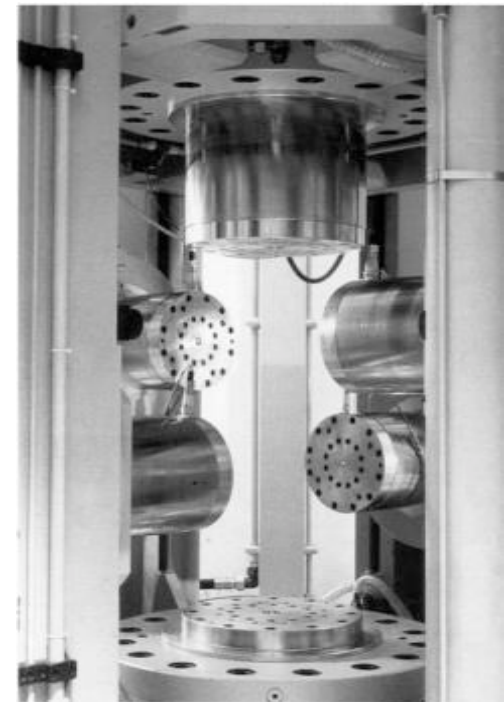

(a)

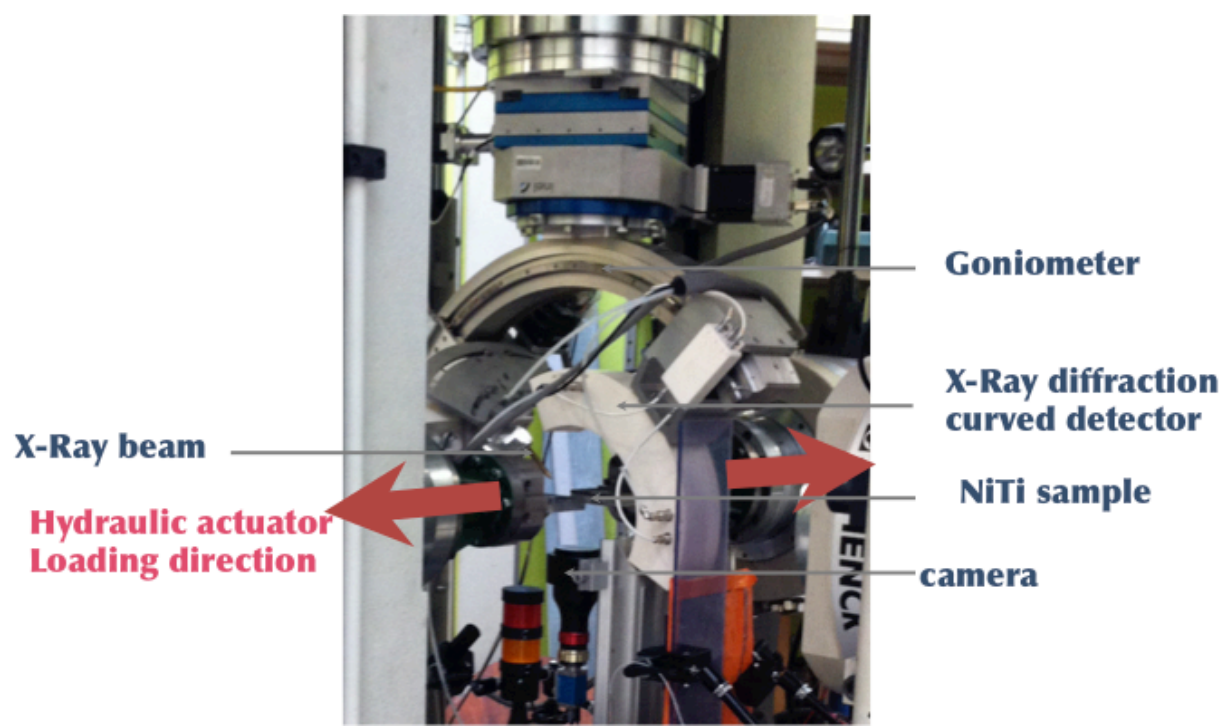

(b)

Figure3 - (a) ASTREE: a complex multiaxial loading machine composed of 6 hydraulic actuators (b) Uniaxial tensile loading experimental device 


\section{RESULTS}

Reference measurement: austenite diffractogram at $50^{\circ} \mathrm{C}$

Theoretical powder diffraction data reported in Figure 4 are used for identifying corresponding diffracting planes for the three possible phases. We performed a first measurement at $50^{\circ} \mathrm{C}$ temperature without any external solicitation. Measured Difractogram is given in Figure 5. According to the DSC curve in Figure 1, the sample should be fully austenitic at $50^{\circ} \mathrm{C}$. We observe a global good agreement between the theoretical diffractogram of the austenitic phase (figure 4a), but some differences occur. For both, main austenite peak is the $\{110\}$ planes diffraction. But intensity ratios between main peak and the others are slightly different from powder diffraction theory. In addition one of the main peaks of austenite corresponding to $\{200\}$ planes does not appear on experimental pattern. We also observe small low angle peak $\left(2 \theta=44.3^{\circ}\right)$ that doesn't match any possible austenite reflection. According to the sample composition and the $\mathrm{Ni}$-Ti phase diagram, $\mathrm{NiTi}_{2}$ precipitates can form during cooling in quasi equi atomic Ti-rich nickel-titanium alloys. $\mathrm{NiTi}_{2}$ have a cubic centered unit cell and the first experimental peak match the peak $\{422\}$ of $\mathrm{NiTi}_{2}$. On the other hand, the relevance of a comparison between experiment carried out on a thin plate sample and a powder diffraction can be questioned due to possible texture effect. EBSD analysis has been performed at ambient temperature. Sample is mainly austenitic according to DSC measurements. EBSD pole figures in Figure 6 highlights a transverse isotropic texture inherited from the forming process. Hence, according to grain orientation, some planes are more or less in favorable diffraction conditions. Presence of texture may consequently alter some diffracting intensities associated with peculiar planes and have an influence on intensities of peaks associate to generated phases (martensite or R-phase). A modeling of the diffracting conditions confirm that the decrease of $\{200\}$ A intensity is associated to the transverse isotropic texture. For further discussions, we will consider a smaller range of $2 \theta$ between $40^{\circ}$ and $60^{\circ}$.
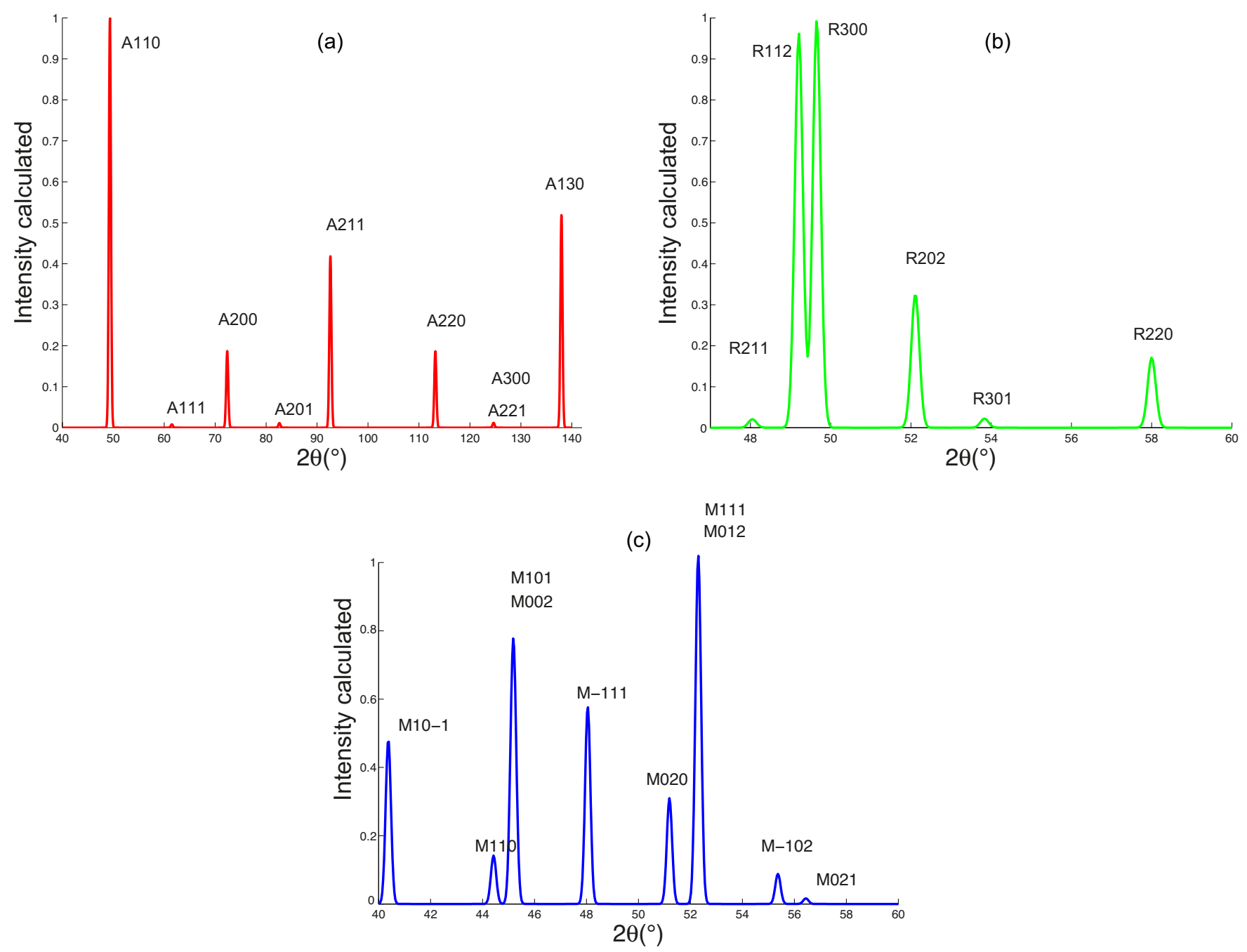

Figure 4 - Calculated powder diffraction for austenite (a), R-phase (b) and martensite (c) phases. 


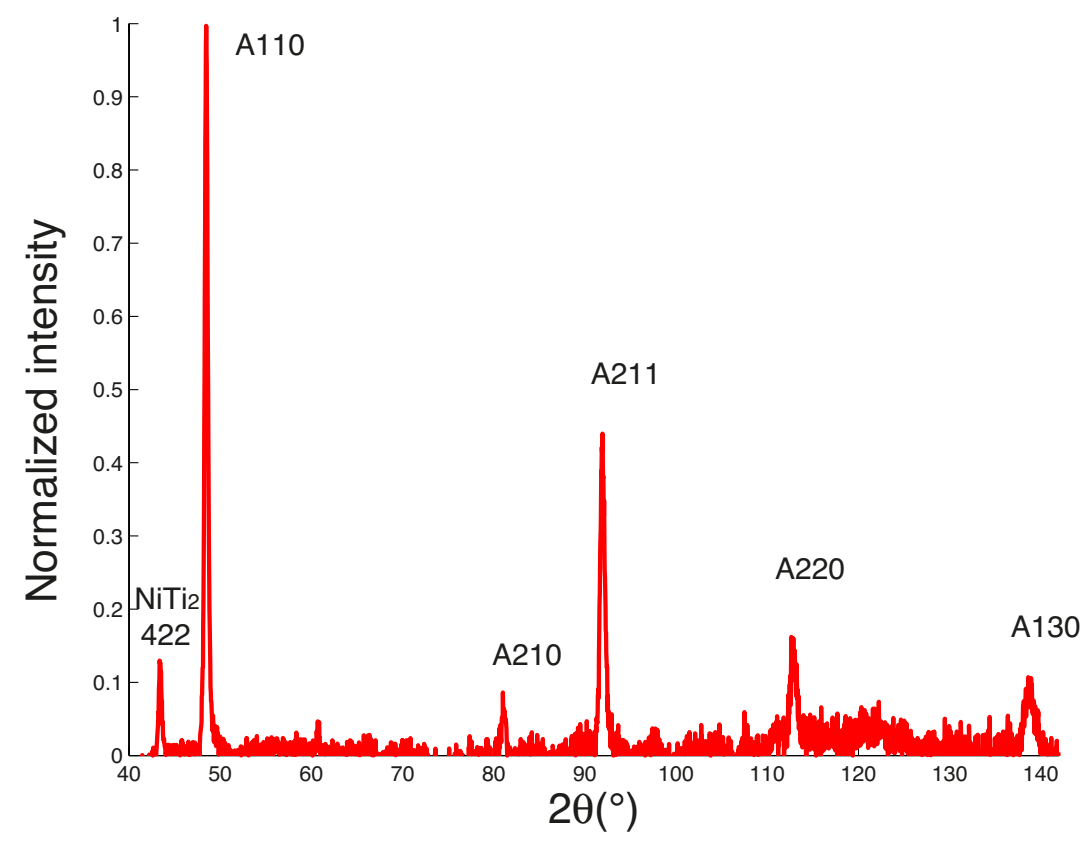

Figure 5 - Experimental diffraction pattern at $50^{\circ} \mathrm{C}$

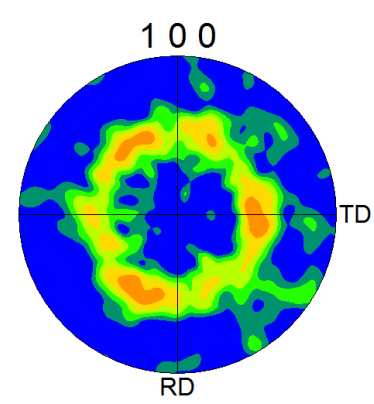

111

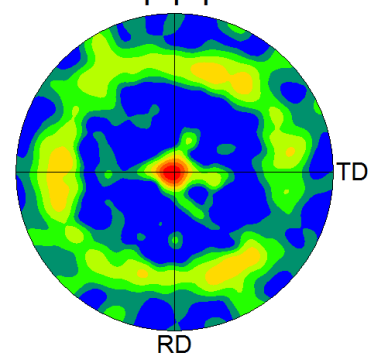

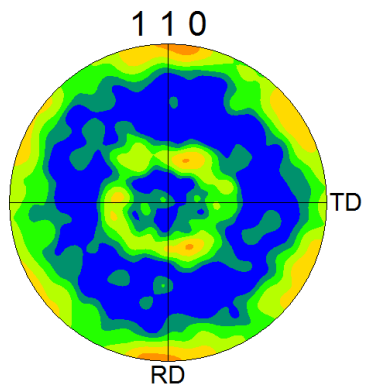

Texture Name: Harmonic: $L=34, H W=5.0$ Calculation Method: Harmonic Series Expansion Series Rank (I): 34 Gaussian Smoothing: $5.0^{\circ}$ Sample Symmetry: Triclinic

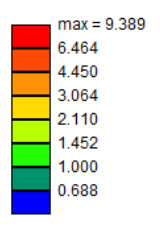

$\mathrm{RD}$ : Rolling direction = tensile direction TD: Transverse direction

Figure $6-\{100\},\{110\}$ and $\{111\}$ poles figures of austenitic phase and associated densities from EBSD analysis.

Results obtained under thermal Solicitations

Sample is first heated to $50^{\circ} \mathrm{C}$. We will first consider a cooling from $50^{\circ} \mathrm{C}$ to $-200^{\circ} \mathrm{C}$ (figure 7), then a heating from $-200^{\circ} \mathrm{C}$ to $50^{\circ} \mathrm{C}$ (figure 8). As previously said, sample is mainly austenitic at $50^{\circ} \mathrm{C}$ with a small amount of $\mathrm{NiTi}_{2}$ precipitates. We see the austenite main pic $\mathrm{A}\{110\}\left(2 \theta=49.4^{\circ}\right)$ and $\mathrm{NiTi}_{2}\{422\}$ peak $\left(2 \theta=44.3^{\circ}\right)$. Cooling to $30^{\circ} \mathrm{C}$, we notice a slight decrease of two peaks. The sample stands mainly austenitic at that temperature. Cooling down to $25^{\circ} \mathrm{C}$ then to $20^{\circ} \mathrm{C}, \mathrm{A}\{110\}$ peak progressively transforms while $\mathrm{NiTi}_{2}\{422\}$ peak is still decreasing. At $10^{\circ} \mathrm{C}, \mathrm{A}\{110\}$ peak splits clearly into to new peaks that can be identified as $\mathrm{R}\{112\}\left(2 \theta=49.2^{\circ}\right)$ and $\mathrm{R}\{300\}\left(2 \theta=49.6^{\circ}\right)$ peaks (see figure $\left.4 \mathrm{~b}\right)$. Precipitate peak is still decreasing. Diffraction pattern is quite the same from $10^{\circ} \mathrm{C}$ to $5^{\circ} \mathrm{C}$. We just notice a slight decrease in R-phase's peaks. R-phase peaks 
consequently decrease from $5^{\circ} \mathrm{C}$ to $-5^{\circ} \mathrm{C}$. At $-5^{\circ} \mathrm{C}$ (diffraction pattern not reported in figure 7 ), new peaks appear that may correspond to ice. In fact, down to $0^{\circ} \mathrm{C}$, ice starts forming on the cooling plate and indeed on the sample surface. This can cause false interpretation and estimation for quantitative analysis. We used then a liquid nitrogen flow to reach a very low temperature down to $-200^{\circ} \mathrm{C}$. Temperature hardly stabilizes under this flow. So we did just one measurement at lower temperature then heated the sample back. This unique measurement permits identification of the main martensite peaks (see figure $4 \mathrm{c})$.

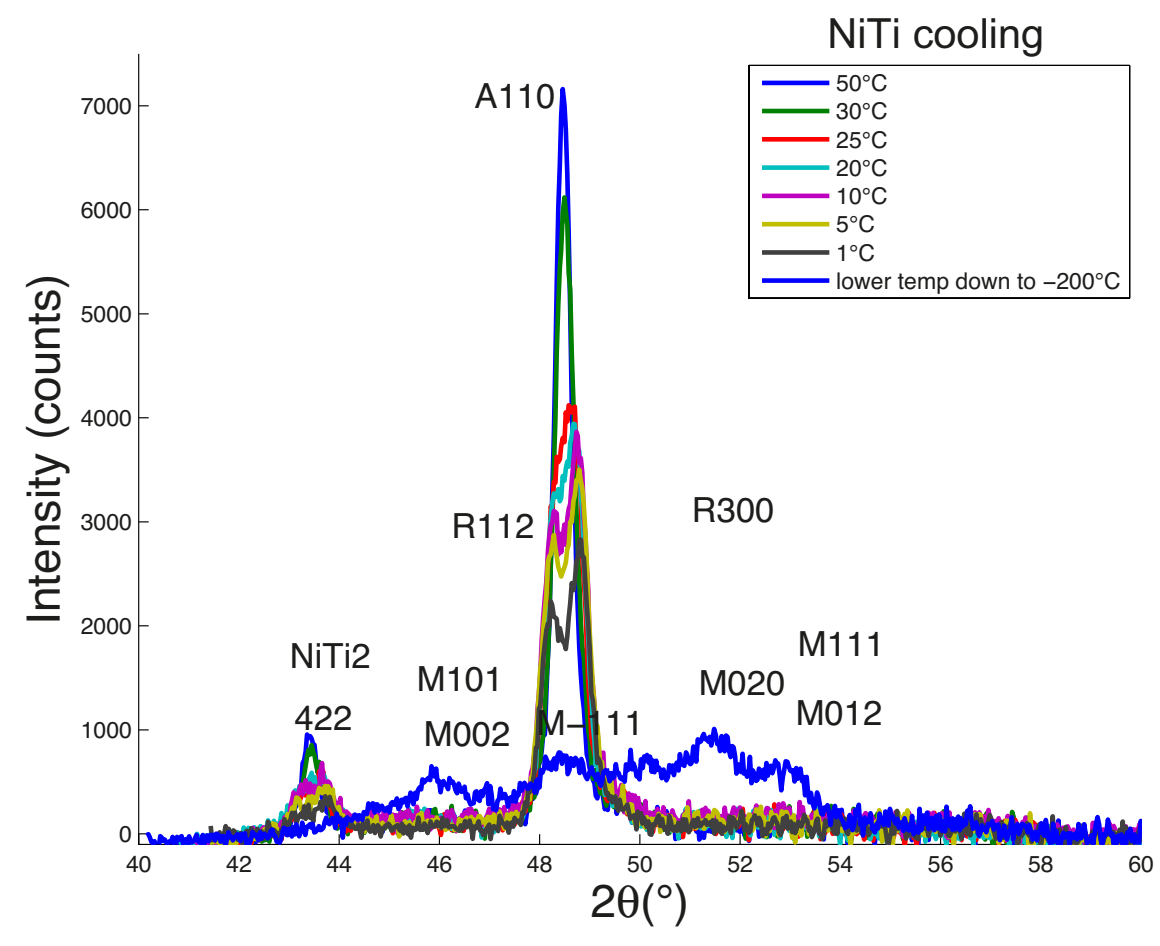

Figure 7 - NiTi Diffraction pattern during cooling test

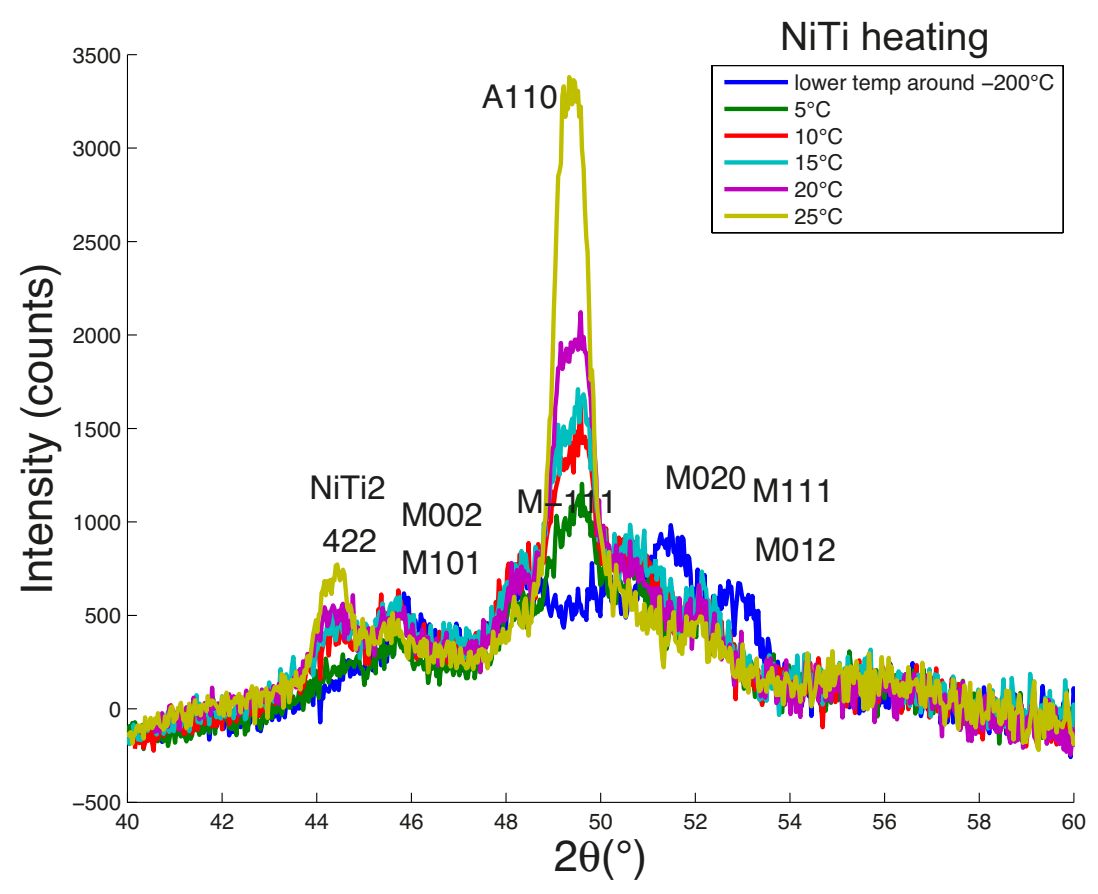

Figure 8 - NiTi Diffraction pattern during heating test 
Figure 8 gives the diffraction results for the sample heated from $-200^{\circ} \mathrm{C}$ to $25^{\circ} \mathrm{C}$ in order to observe the inverse transformation. The main observation is that inverse and the direct transition patterns are different. This result is in accordance with the DSC predictions since reverse and direct transformations do not occur at the same temperature. On the other hand it seems clear now that the martensite transforms directly in austenite without any transient transformation into Rphase. The sample is quite mainly austenitic at $25^{\circ} \mathrm{C}$. A precise quantitative analysis would require to quantify first the texture effect on the austenite diffraction pattern, and secondly its effect on $\mathrm{R}$ phase and martensite patterns. Besides many errors can occur since martensite peaks are quite weak comparing to the background. Some other limits for identification can be addressed: diffuse transformation, convoluted peaks, doubled peaks... Quantitative estimation of phase fraction requires a very careful analysis of the dispersion sources. This work is in progress.

Results obtained during uniaxial tensile test at the room temperature

The measured engineering stress $\left(\sigma=\mathrm{F} / \mathrm{S}_{0}\right)$ versus engineering strain $\left(\varepsilon=\Delta \mathrm{l} / \mathrm{l}_{0}\right)$ curve is given in Figure 9 . The observed plateau is specific to pseudoelastic behavior, i.e. stress induces a transformation from austenite to martensite. Diffraction measurements have been carried out for various stress/strain points of this curve. The diffraction is realized perpendicularly to the applied stress. Results are reported in figure 10. At the room temperature $\left(\mathrm{T}=26^{\circ} \mathrm{C}\right)$ and without applied stress $(12 \mathrm{MPa}$ - sample positioned in the machine), the austenitic state is clearly dominant. Applying $460 \mathrm{MPa}$ stress level, we observe a little change in the peaks position. This shift is associated with a small change of lattice parameters due to stress. Increasing applied stress to $540 \mathrm{MPa}$, we notice a clear decrease of $\mathrm{A}\{110\}$ and $\mathrm{NiTi}_{2}\{422\}$ peaks and a concomitant appearance of martensite $\mathrm{M}\{020\}$ peak. Increasing applied stress from $540 \mathrm{MPa}$ to $750 \mathrm{MPa}, \mathrm{NiTi}_{2}\{422\}$ peak progressively disappears. $\mathrm{A}\{110\}$ peak is still decreasing while $\mathrm{M}\{020\}$ peak intensity is increasing. Meanwhile smaller martensite peaks like $\mathrm{M}\{101\}$ and $\mathrm{M}\{002\}$ just appear. Peaks position continue a progressive shifting to higher angles due to increasing stress. Up to $750 \mathrm{MPa}$ diffraction pattern does no longer evolve. In stress driven transformation, we see that $\mathrm{M}\{020\}$ is the main diffracting plane. Unlike uniform temperature driven transformation, martensite variants oriented along the loading direction are preferably selected with the mechanical loading. Another important feature is the complete absence of R-phase planes. This result is in accordance with the small transformation strain of this phase and small associated thermomechanical coupling [5]. Quantitative estimation of phase volume fraction would require the same precaution than for results carried out under thermal loading.

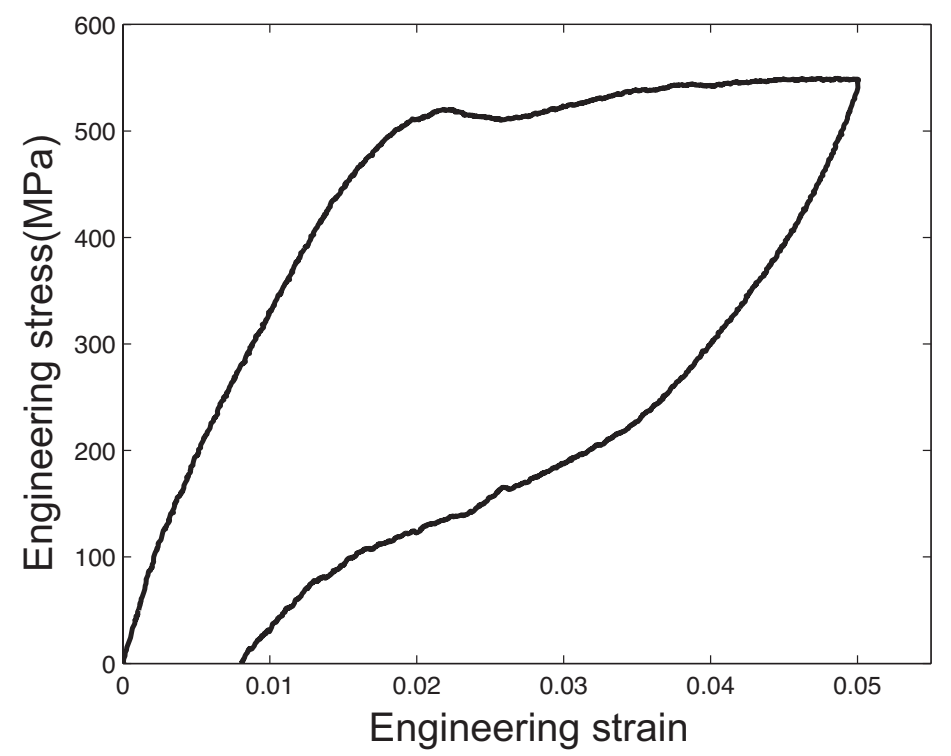

Figure 9 - Engineering stress-strain curve for NiTi SMA at the room temperature (rate: $0.01 \mathrm{~mm} / \mathrm{s}$ ). 


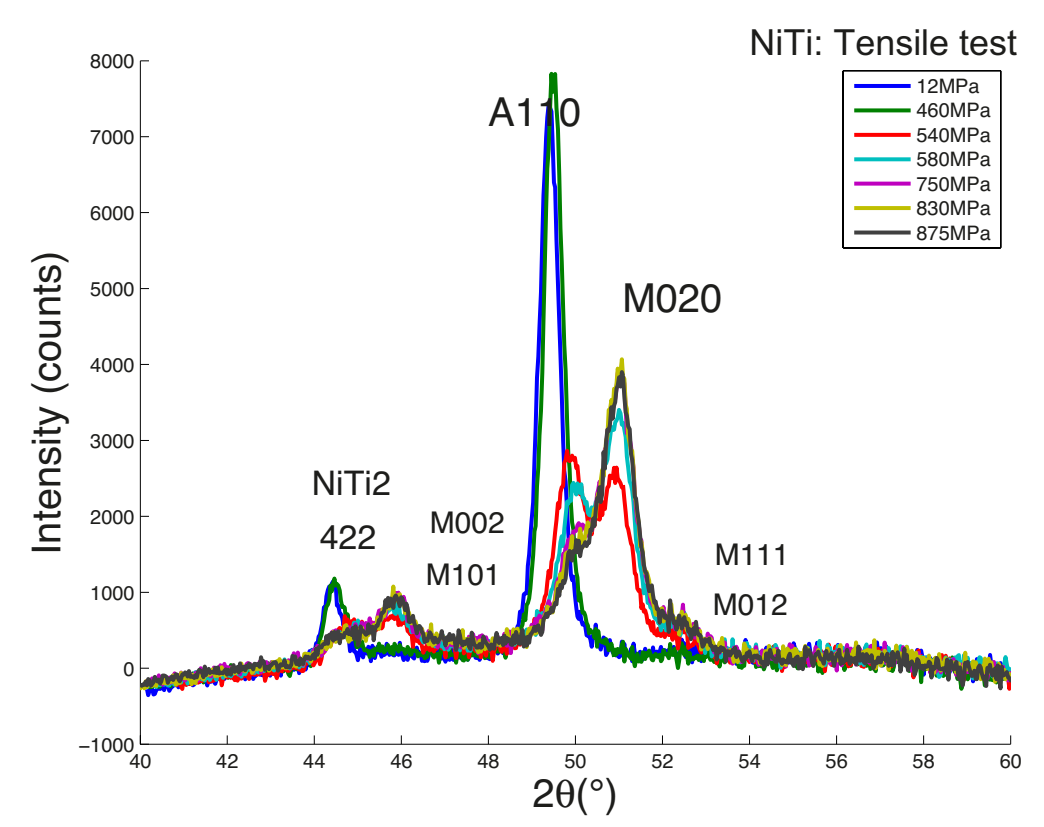

Figure 10 - NiTi diffraction pattern during uniaxial tensile loading at the room temperature

\section{CONCLUSION}

In Situ X ray measurements offer an efficient way for characterizing martensitic transition at the microscale. Some valuable information have been carried out concerning the studied NiTi sample: presence of $\mathrm{NiTi}_{2}$ precipitates; transient R-phase appearance with temperature; path differences between heating and cooling due to germination effects; martensite variants selection during the mechanical loading and non activation of R-phase transformation during stress driven tests. This work offers a lot of interesting perspectives. In situ $\mathrm{X}$ ray diffraction is especially a very promising tool to validate multiscale and multiphased model estimations [6]. Of course, quantitative analysis over diffraction pattern is needed to extract fractions from experiments. For a good quality quantitative analysis, we need to accurately control the test conditions (e.g. apprearance of ice during cooling), the acquisition precision (peak height versus background) and sample's history (presence of precipitates, texture effect, residual stress level). These parameters should be taken into account for identification as well as volume fraction evaluation. The sample texture influences austenite diffractogram pattern. Its role on the X-ray signature of derived phases (R-phase and martensite) must be carefully taken into account. Some others limits like the small signal/background ratio for martensite peaks for example do exist. A Rietveld quantitative analysis taking into account texture correction for each phase will be implemented to get a more precise estimation of phase volume fractions. The multiscale model developed at LMT-Cachan is able to predict thermomechanical SMA behavior under thermal and multiaxial loadings. Hence, it would be very interesting in a second approach to perform quantitative in situ X ray diffraction under complex conditions mixing multiaxial stress and thermal loading.

\section{REFERENCES}

[1] A. Maynadier, D. Depriester, K. Lavernhe-Taillard, O. Hubert, "Thermo-mechanical description of phase transformation in Ni-Ti Shape Memory Alloy", Procedia Engineering, 10: 2208-2213, (2011)

[2] B.D. Cullity, "Elements of X-Ray Diffraction", Addison-Wesley publishing company, (1978) (second edition)

[3] M. Pattabi, K. Ramakrishna, K.K. Mahesh, Corrigendum to "Effect of thermal cycling on the shape memory transformation behavior of NiTi alloy: Powder X-ray diffraction study", Mater. Sci. Eng. A., 448 : 33-38, (2007)

[4] J. Uchila, 1, F.M. Braz Fernandesb, K.K. Mahesha, "X-ray diffraction study of the phase transformations in NiTi shape memory alloy", Materials Characterization, $58: 243-248$, (2007)

[5] K. Battacharya, "Microstructure of Martensite : why it forms and how it gives rise to the shape memory effect ?", Oxford series on materials modelling, (2003)

[6] M. D. Fall, K. Lavernhe-Taillard, A. Maynadier and O. Hubert, "Validation of Shape Memory Alloys Multiscale Modeling thanks to in-situ X-Rays Diffraction", 16th International Conference on Experimental Mechanics (ICEM 2014), accepted. 